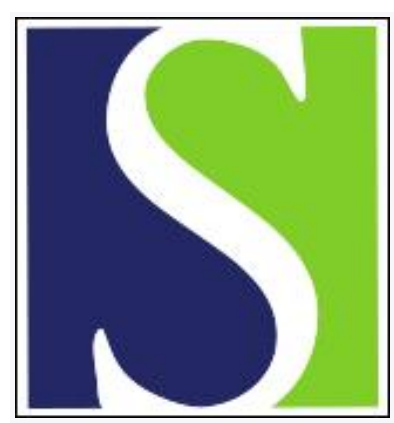

Scand J Work Environ Health 1987;13(3):255-257

https://doi.org/10.5271/sjweh.2054

Issue date: Jun 1987

Comparison of methods used for measuring the electrostatic field of video display terminals.

by Konttinen S, Juutilainen J, Raunemaa T

This article in PubMed: www.ncbi.nlm.nih.gov/pubmed/3616556

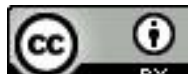




\title{
Comparison of methods used for measuring the electrostatic field of video display terminals
}

\author{
by Soile Konttinen MSc, Jukka Juutilainen MSc, Taisto Raunemaa PhDi
}

\begin{abstract}
KONTTINEN S, JUUTILAINEN J, RAUNEMAA T. Comparison of methods used for measuring the electrostatic field of video display terminals. Scand $J$ Work Environ Health 13 (1987) 255-257. The electrostatic field exposure of video display terminal (VDT) operators was measured with different methods. Using the Wilson plate method the field strength at different locations at the face of three human subjects working with a VDT was determined. The strongest fields were found at protruding facial features. Measurements were also made with a measuring instrument known as a field mill. Comparative measurements were made with the field mill as such and combined with a metal plate or a hemisphere. The measured field strength was highly dependent on the method of measurement. A conducting hemisphere (diameter $0.20 \mathrm{~m}$ ), used in combination with the field mill, was found to be a useful model of the human head in electrostatic measurements.
\end{abstract}

Key terms: electrostatic field, electrostatic measurements, VDT.

The operator of a video display terminal (VDT) is exposed to electrostatic fields. The field strength at the operator's position varies between different VDT models from zero to tens of kilovolts per meter $(3,5,10$, 15). The biological significance of electrostatic fields is not known, but it has been assumed that it may be associated with the facial skin rashes of some VDT operators $(1,3,7,9,12,14)$.

Different methods have been used to measure the electrostatic fields of video display terminals. In two studies $(4,6)$ the field strength was measured with a field mill positioned centrally in front of the screen. The field mill was grounded, and the field strength was noted. Another method is to place a large grounded metal plate parallel to the screen and to measure the field strength at the surface of this plate (5) or through a hole in the plate made for the sensor of the field mill (10). Neither of these methods gives a realistic estimate of the electric field strength on the skin of the operator.

When a conducting object (such as a human body) is placed in the electric field of a terminal, the field is perturbed. The electric field strength at the surface of the conducting object depends strongly on the geometry of the object $(5,11)$. When a longitudinal object such as a field mill is introduced into the field, a stronger field is measured than at the surface of a flat plate. The field strength around a human head is probably between these two cases.

The purpose of this study was to study the usability of a conducting hemisphere as a model of the human

\footnotetext{
1 Department of Environmental Hygiene, University of Kuopio, Kuopio, Finland.
}

Reprint requests to: $\mathrm{Mr} \mathrm{J}$ Juutilainen, Department of Environmental Hygiene, University of Kuopio, PO Box 6, SF-70211 Kuopio, Finland. head. In this report, electrostatic field strengths measured with this model are compared to those measured on the skin of VDT operators with the Wilson plate method. In order to facilitate comparison of the field strengths measured with different methods, also results obtained with the field mill as such and in combination with a flat metal plate are reported.

\section{Methods}

The electrostatic field strength was measured with an Eltex Q 475/C field mill. The calibration of the field mill was checked between two $(0.25 \times 0.25 \mathrm{~m})$ metal plates. The sensor of the field mill was inserted through a hole in one of the plates, and a high voltage of 2.5 $\mathrm{kV}$ was applied to the other plate. When the distance between the plates is small compared to the dimensions of the plates, the electric field is nearly homogeneous, and the field strength can be calculated as voltage per distance (8). The field mill was found to give correct readings.

A hemisphere (diameter $0.20 \mathrm{~m}$ ) made of steel grid was used as a model of the human head. A circular hole was cut at the center of the hemisphere for the sensor of the field mill. Both the hemisphere and the field mill were grounded during the measurements.

For comparison, measurements were also made with the field mill in combination with a flat metal plate. A $0.25 \times 0.25-\mathrm{m}$ aluminum plate was used, and the sensor of the field mill was inserted through a circular hole at the center of the plate.

The Wilson plate (13) was used for measuring the electrostatic field at the skin surface of VDT operators. The Wilson plate is a simple instrument for measuring the field intensity on a grounded plane. It consists of an insulated metal plate connected to an electrometer. The plate is screened by a grounded plate 
and is grounded for a moment. When the screen is removed, the reading of the electrometer (in coulombs) is proportional to the field intensity. We used a $30 \times 30$-mm copper plate made of printed circuit board connected to a Keithley Instruments Model $610 \mathrm{C}$ electrometer. A larger plate $(70 \times 50 \mathrm{~mm})$ with a handle was used for screening the measuring plate. This measuring system was calibrated in a homogeneous electrostatic field. During the measurements the VDT operator was grounded. Every measurement was repeated several times, and the average was calculated.

The field mill in combination with the hemisphere was used for measuring the electrostatic field of several VDT models. The measurements were made in usual office rooms. The operator was not present when these measurements were performed. During the measurements the temperature was between 18 and $22^{\circ} \mathrm{C}$, and the relative humidity varied from 10 to $22 \%$.

\section{Results}

The measured electrostatic field in front of a video display terminal is highly dependent on the method of

Table 1. Comparison of the field strengths $(\mathrm{kV} / \mathrm{m})$ measured with different methods in front of two video display terminals (VDT).

\begin{tabular}{lccc}
\hline $\begin{array}{l}\text { Distance } \\
\text { from the } \\
\text { VDT }(\mathrm{m})\end{array}$ & $\begin{array}{c}\text { Field mill } \\
\text { as such }\end{array}$ & $\begin{array}{c}\text { Field mill } \\
\text { with the } \\
\text { hemisphere }\end{array}$ & $\begin{array}{c}\text { Field mill } \\
\text { with the flat } \\
\text { metal plate }\end{array}$ \\
\hline Terminal I & (Olivetti CRT 250) & & \\
0.10 & 170 & 150 & 120 \\
0.15 & 100 & 75 & 60 \\
0.20 & 60 & 50 & 35 \\
0.30 & 30 & 22 & 15 \\
0.40 & 15 & 12 & 7 \\
Terminal 2 (WYSE WY85) & & \\
0.10 & 150 & 120 & 100 \\
0.15 & 90 & 70 & 55 \\
0.20 & 55 & 40 & 30 \\
0.30 & 28 & 20 & 12 \\
0.40 & 13 & 10 & 6 \\
\hline
\end{tabular}

Table 2. The electrostatic field strength $(\mathrm{kV} / \mathrm{m})$ measured with the Wilson plate on the face of operators of video display terminals compared to the values measured with other methods (measuring distance $0.30 \mathrm{~m}$ ).

\begin{tabular}{|c|c|c|c|}
\hline & \multicolumn{3}{|c|}{ Subject } \\
\hline & 1 (man) & 2 (woman) & 3 (man) \\
\hline \multicolumn{4}{|l|}{$\begin{array}{l}\text { Measurements with } \\
\text { the field mill }\end{array}$} \\
\hline As such & 23 & 23 & 30 \\
\hline With the hemisphere & 17 & 17 & 22 \\
\hline With the flat plate & 12 & 12 & 15 \\
\hline \multicolumn{4}{|l|}{$\begin{array}{l}\text { Measurements with the } \\
\text { Wilson plate }\end{array}$} \\
\hline At the forehead & $16(0.7)$ & $18(0.5)$ & $19(1.4)$ \\
\hline At the cheek & $14(0.3)$ & $13(0.5)$ & $16(0.6)$ \\
\hline At the chin & $19(0.3)$ & $17(0.8)$ & $24(0.9)$ \\
\hline
\end{tabular}

measurement (table 1). At the distance of $0.30 \mathrm{~m}$ or more, the Eltex field mill as such gives twice the values given by the field mill in combination with the flat metal plate. The values obtained with the hemisphere are between these two extremities.

With the Wilson plate the strongest fields were measured at protruding facial features (table 2). Still higher values would probably be measured at the tip of the nose, but the size of the Wilson plate used did not permit such measurements. The field mill appeared to give the most realistic estimate of the average electrostatic field intensity on the face when it was used in combination with the hemisphere.

The electrostatic field measured with the field mill and the hemisphere varied from 0 to $40 \mathrm{kV} / \mathrm{m}$ at the distance of $0.30 \mathrm{~m}$ in front of various VDT models (table 3). As expected, these values are higher than those $(0-30 \mathrm{kV} / \mathrm{m})$ measured at the surface of a flat metal plate $(5,10)$.

\section{Discussion}

The results of the measurements with the field mill demonstrate the importance of measuring geometry in estimating the electrostatic field exposure of VDT operators. The relative difference between the three methods of measurement increases with increasing distance from the terminal. According to Paulsson et al (10) the electrostatic field is proportional to $r^{-1}$ "close" to the screen and to $\mathrm{r}^{-3}$ at larger distances (r) from the screen. However, at the intermediate distances used in the present investigation, there is no simple relationship between field strength and distance. The exact relationship depends on the shape and size of the measuring system and the screen.

At present, not much is known of the biological effect of electrostatic fields. It has been assumed that the skin problems possibly associated with video display terminals are due to enhanced aerosol deposition on the operator's face because of the electrostatic field (4). In this case the exact value of the electrostatic field is perhaps not so important as the physicochemical properties of the aerosol particles and possibly the elec-

Table 3. Field strengths $(\mathrm{kV} / \mathrm{m})$ measured in front of different video display terminals (VDT).

\begin{tabular}{lrrr}
\hline \multirow{2}{*}{ VDT } & \multicolumn{3}{c}{ Distance from the VDT } \\
\cline { 2 - 4 } & $0.10 \mathrm{~m}$ & $0.30 \mathrm{~m}$ & $0.40 \mathrm{~m}$ \\
\hline Data General D211 & 170 & 25 & 15 \\
Digital Decscope CVT52-AP & 80 & 15 & 10 \\
Lear Siegler ADM 32 & 140 & 25 & 20 \\
Lear Siegler ADM 32 & 115 & 20 & 10 \\
Nokia Mikromikko 2 & 130 & 25 & 15 \\
Nokia VDU 52 & 170 & 40 & 20 \\
Nokia VDU 202 & 7 & 2 & 1 \\
Nokia VDU 202 & 2 & 0 & 0 \\
Philips VDU Local & 35 & 7 & 3 \\
WYSE WY85 & 155 & 25 & 15 \\
\hline
\end{tabular}


trostatic charge of the operator. In this study, stronger fields were measured at the forehead and chin than at the cheek, which is the usual location of the reported skin problems of VDT operators.

In the case that exact measurement of the electrostatic field exposure is necessary, the Wilson plate is probably the most exact method. However, the measuring procedure is sensitive to disturbances, and very careful operations are necessary to get reproducible results. A limitation of this method is that it can be used only on grounded surfaces, ie, the potential of the VDT operator must be zero. In reality, the potential of a sitting person can be some tens or hundreds of volts (or even thousands for short durations), positive or negative $(4,6)$.

A realistic estimate of the electrostatic field strength at a VDT operator's face can be obtained with a field mill equipped with a conducting hemisphere that operates as a model of the human head. The measuring system can be brought to any electrostatic potential to simulate real exposure conditions. The field mill without the hemisphere gives readings that are too high. It could possibly be used to estimate the worst case exposure, but different models of field mills would give different results. The field mill in combination with a flat metal plate gives readings that are too low in comparison to the values measured at the forehead and chin of VDT operators. However, if one wants to measure the field emission from a video display terminal (instead of the exposure of the operator), it may be useful to estimate the potential of the screen surface. One can make this estimation by using a flat metal plate at a close distance (in order to obtain a near homogeneous field) and calculating the approximate potential by multiplying the field strength by the distance (1).

In conclusion, the field mill combined with a conducting hemisphere (diameter $0.20 \mathrm{~m}$ ) appeared to give a relatively good estimate of the average electrostatic field strength at the operator's face. Because of the simplicity of the measurement, it could be used as a standard method in measuring the electrostatic field exposure of VDT operators.

\section{References}

1. Bergqvist UOV. Video display terminals and health: $A$ technical and medical appraisal of the state of the art. Scand J Work Environ Health 10 (1984): suppl 2, 87 p.

2. Bergqvist UOV. Bildskärmarbete och hälsa: En utvärdering av kunskapsläget. Arbetarskyddsverket, Stockholm 1986. (Arbete och hälsa 9: 1986).

3. Bergqvist UOV, Wibom RI, Nylen P. Electrostatic fields at VDT work stations - A review. In: Swedish National Board of Occupational Safety and Health. Proceeding of the international scientific conference: Work with display units, Stockholm, May 12-15 1986. Part I. Stockholm 1986, pp 45-48.

4. Cato Olsen W. Electric field enhanced aerosol exposure in visual display unit environments. Chr Michelsen Institute, Bergen 1981. (CMI 803604-1).

5. Harvey SM. Electric-field exposure of persons using video display units. Bioelectromagnetics 5 (1984) $1-12$.

6. Knave BG, Wibom RI, Bergqvist UOV, Carlsson LLW, Levin MIB, Nylen PR. Work with video display terminals among office employees: II Physical exposure factors. Scand J Work Environ Health 11 (1985) $467-474$.

7. Linden V, Rolfsen S. Video computer terminals and occupational dermatitis. Scand J Work Environ Health 7 (1981) 62-63.

8. Misakian M. Calibration of flat $60-\mathrm{Hz}$ electric field probes. Bioelectromagnetics 5 (1984) 447-450.

9. Nielsen A. Facial rash in visual display unit operators. Contact Dermatitis 8 (1982) 25-28.

10. Paulsson L-E, Kristiansson I, Malmström I. Strålning från dataskärmar, arbetsdokument a 84-08. Statens Strålskyddsinstitut, Stockholm 1984.

11. Pfützner $\mathrm{H}$. The standardization of experimental investigations of biological effects of low frequency electric and magnetic fields. Int J Biometeorol 23 (1979) 271278.

12. Rycroft RJG, Calnan CD. Facial rashes among visual display unit operators. In: Pearce BG, ed. Health hazards of VDTs? John Wiley \& Sons, Chichester 1984, pp 13-15.

13. Tammet H, Salm J, Tamm E. Measurement of air ions and aerosols. In: Gualtierotti R, Kornblueh IH, Sirtori $\mathrm{C}$, ed. Bioclimatology biometeorology and aeroionotherapy. Carlo Erba Foundation, Milan 1968, pp 57-62.

14. Tjønn HH. Report of facial rashes among VDU operators in Norway. In: Pearce BG, ed. Health hazards of VDTs? John Wiley \& Sons, Chichester 1984, pp 17-23.

15. Ungethüm E. Elektrostatiska fält $i$ närheten av dataskärmar och dess betydelse för transport av luftburen förorening: Resume, 33. In: Yrkeshygienisk institut. Nordiske yrkeshygieniske möte. Oslo 1984, p 17.

Received for publication: 8 July 1986 